\title{
Design and Implementation of Classroom Inspection System for Teaching Process
}

\author{
Sixin Zou ${ }^{1}$, Guimei Qiu ${ }^{2}$, Guoxin Fang ${ }^{3}$, Jun Li ${ }^{1, ~ * ~}$ \\ ${ }^{1}$ College of Computer Science, Guangdong Polytechnic Normal University, Guangzhou, China \\ ${ }^{2}$ Guangzhou Electronics Information School, Guangzhou, China \\ ${ }^{3}$ Guangdong Hengdian Information Technology Co., Ltd., Guangzhou, China
}

\section{Email address:}

499574679@qq.com (Sixin Zou), 459474448@qq.com (Guimei Qiu),6603885@qq.com (Guoxin Fang), 844341781@qq.com (Jun Li)

${ }^{*}$ Corresponding author

\section{To cite this article:}

Sixin Zou, Guimei Qiu, Guoxin Fang, Jun Li. Design and Implementation of Classroom Inspection System for Teaching Process. Science Innovation. Vol. 7, No. 3, 2019, pp. 106-109. doi: 10.11648/j.si.20190703.15

Received: July 18, 2019; Accepted: August 13, 2019; Published: August 27, 2019

\begin{abstract}
The paper designs a classroom inspection system based on mobile internet, and conducts inspections and records on the classroom teaching process through mobile phones and tablet computers, and checks the classroom teaching situation, teaching environment, student discipline, and student learning status. As an assistant teaching management system of secondary vocational schools, the classroom inspection system designed in this paper provides real-time and user-friendly operation functions for school administrators and teaching administrators. At present, this system is in trial operation in a secondary vocational school in Guangzhou. By arranging inspections by school-level cadres and teaching and management personnel, we will grasp the classroom teaching situation in time, and pay attention to the major problems found in the inspections in a timely manner. At the same time, we will find the shining points of teachers and students in the teaching process and assist young teachers in secondary vocational schools to solve problems in the classroom. The establishment of a standardized inspection system to ensure the routinization of classroom teaching has a positive role in improving the quality of classroom teaching.
\end{abstract}

Keywords: Mobile Internet, Classroom Inspection System, Assistant Teaching Management System, Secondary Vocational Schools

\section{面向教学过程的课堂巡查系统设计与实现}

\author{
邹思听 ${ }^{1}$, 丘桂梅 ${ }^{2}$, 方国金 $^{3}$, 李军 ${ }^{*}$ \\ 1 广东技术师范大学计算机科学学院, 广州, 中国 \\ 2 广州市电子信息学校, 广州, 中国 \\ ${ }^{3}$ 广东恒电信息科技股份有限公司, 广州, 中国
}

\section{邮箱}

499574679@qq.com（邹思听），459474448@qq.com（丘桂梅），6603885@qq.com（方国釒金），844341781@qq.com（李军）

摘要：论文设计了基于移动互联网的课堂巡查系统, 通过手机、平板电脑等对课堂教学过程进行巡查和记录, 检查教 师课堂教学情况、教学环境、学生纪律、学生学习状况等。论文设计的课堂巡查系统作为中等职业学校的辅助教学管 理系统, 面向学校教务、教学管理人员, 提供实时、人性化的操作功能, 开发的实时交互式课堂巡查系统在广州某中 职学校实现了试运行。通过安排校级干部和教学教务管理人员巡查, 及时掌握课堂教学情况, 对巡查中发现的重大问 题及时引起学校的重视, 同时发现教学过程中师生的闪光点, 协助中职学校中年轻老师解决课堂中的问题。建立规范 的巡查制度，保证课堂教学常规化，对提高课堂教学质量有积极的促进作用。 
关键词: 移动互联网, 课堂巡查系统, 辅助教学管理系统, 中等职业学校

\section{1. 引言}

中等职业学校招生总量扩大, 但生源质量却难以得到 保证[1]。中职学校的学源多数是因为中考成绩不理想, 没 考上普通高中, 失去原有的努力方向, 潜意识里认定自己 是差生, 这种心理暗示使他们失去了学习的热情, 学习态 度急慢, 求知欲不强, 影响了中等职业学校的教学质量[2]。 为了保证中等职业学校的教育质量, 建立适合中等职业学 校的教学质量保障与监督体系 [3], 课堂巡查系统是探讨提 高中职学校教学质量的辅助教学管理系统 [4]。针对中职学 校课堂巡查的现状, 制定更为完善的课堂巡查规则, 设计 基于移动互联网的课堂巡查系统, 提高课堂巡查效率 [5]。

\section{2. 中等职业学校课堂巡查}

中等职业学校课堂巡查是保障课堂教学过程质量的一 种辅助教学管理系统, 通过课堂巡查完善课堂教学过程的监 控, 督促教职人员做好本职工作, 促进中等职业教育的可持 续发展[6]。中等职业学校课堂巡查系统是由教学管理部门对 课堂教学过程进行巡查, 采集有关课堂教学过程的信息, 进 行汇总和分析, 并将信息整理反馈给教学管理部门和相关教 师。通过反馈的信息, 帮助相关教师提高课堂教学过程的管 理能力, 教学管理部门改进巡查流程, 巡查指标[7]。中等职 业学校的课堂巡查流程是: (1) 巡查, 管理人员在巡查课 室时, 通过查找课程表找到相应的班级; (2) 记录, 将课 堂巡查情况记录在记录纸上; (3) 统计, 教研管理员将所 有巡查情况记录收集起来, 录入进电脑, 并做成表格文档进 行统计; (4) 反馈, 通过统计得出的结果, 反馈到相关教 学管理部门, 同时也反馈给相关授课教师。

建立完善的巡查制度, 对课堂的教学管理、教学状况、 教学环境等方面进行巡查, 发现课堂教学过程存在的问题 要及时反馈, 保证课堂教学质量 $[8]$ 。关注管理人员的专业 素质及综合素养的提升, 有效的提高工作效率, 为学校教 学管理工作服务[9-10]。

表1 广州市某中职学校巡查记录的内容。

\begin{tabular}{llll}
\hline \multirow{2}{*}{ 序号 } & 巡查记录的内容 & & \\
\cline { 2 - 4 } & 教师 & 学生 & 教室 \\
\hline 1 & 在岗否 & 睡觉否 & 门窗有没关 \\
2 & 精神饱满否 & 玩手机否 & 教学设备开启否 \\
3 & 玩手机否 & 喧闹否 & 学生待在教室否 \\
\hline
\end{tabular}

中等职业学校巡查的对象是学生和教师。监督学生课 堂学习情况, 对教师教学过程中的教学行为、教学观念、 教学模式、教学方式等进行巡查。巡查记录的内容主要分 为三个部分: (1) 教师的教学情况: 是否在岗, 在教学 过程中的精神面貌, 是否有玩手机的现象; (2) 学生在 上课时的学习状况：是否有玩手机、睡觉、喧闹等情况; （3）教室环境状况: 该课室当没有课时, 是否有学生留
在教室的情况, 或该课室当没有课时, 教学设备、门、窗 是否关好的情况等。该校巡查记录内容如表1所示。

巡查过程形式化严重: 中等职业学校课堂巡查不易被 领导重视, 课堂巡查较为随意, 不按照固定的流程巡查。 如: 课堂巡查人员至少两人, 每周进行课堂巡查一次, 巡 查时会出现两个人在同一时间段内巡查同一间教室。有的 管理人员巡查课堂时只是应付式的巡查几间教室, 导致巡 查后的数据很少, 无法准确的反映课堂教学过程的真实情 况。

巡查的流程繁杂: 目前的课堂巡查模式还在沿用传统 的方法, 以及课堂巡查的内容也没有与时俱进。校内管理 人员对中等职业学校课堂巡查的数据采集和记录, 惯用的 方式是采用手写记录, 再录入到电脑中进行汇总, 这样采 集的信息方式过于繁杂, 不利于数据的统计, 不能得到很 好的反馈信息。

巡查信息反馈不到位: 目前中等职业学校的课堂巡查 信息只是进行了记录, 没有汇总分析和反馈异常问题, 导 致课堂巡查形如虚设, 学生和教师对自身的课堂表现不能 得到很好的反思。

通过课堂巡查直接记录课堂教学情况, 并将获得的课 堂教学情况直接反馈到服务端进行汇总。巡查平台获取到 课堂教学效果的数据, 通过服务器进行汇总。教学管理人 员从汇总的信息中能分析出当前课堂教学过程中存在的 问题, 并对问题进行深入剖析, 为学校的教学环节提供建 议与方案。从而提高学校课堂教学过程监控的科学性和有 效性。

\section{3. 课堂巡查系统的设计}

课堂巡查系统是实现信息化建设和教学监控手段的 结合。利用巡查平台提高现代信息化课堂巡查能力, 增加 课堂巡查的科学性、有效性以及公正性[11]。巡查系统在 设计上做到全过程管理, 涉及课堂教学活动的所有相关环 节, 包括巡查的流程、巡查内容的设置、管理人员的安排 等, 最后还要有反馈控制, 形成一整套完整的循环机制。 本文设计的巡查系统包含四个部分, 具体设计如下。

巡查队伍的组建: 基于全面质量管理为理论基础的巡 查系统, 将全面质量管理贯穿到每个课堂教学管理环节中, 全体教职员工参与到巡查中。巡查队伍分为两组, 第一组 是巡查小组, 巡查小组是负责日常的课堂巡查工作, 由教 研员组成, 巡查小组每日随机抽选一节课, 对学校的所有 课室进行巡查。第二组是辅助巡查小组, 由除了巡查小组 成员外的所有教学管理人员组成, 辅助管理人员每周随机 抽选一节课, 对学校的所有课室进行巡查。

巡查记录的设计: 综合运用现代信息技术和教学质量 管理方法, 通过各部门的相互配合, 对课堂进行全方面、 全过程的巡查。管理人员利用本文设计的巡查平台进行巡 查, 节省了纸质记录巡查信息的时间, 减轻了管理人员的 工作量, 提高课堂教学管理的效率。 
本文设计的APP巡查系统, 借助课堂巡查进行课堂巡 查, 巡查一间教室的步骤是: 在课堂巡查平台上点选对应 的课室, 选择需要记录的情况, 最后点击保存即可。这种 信息化的巡查方式, 省去了在纸质课程表上查找班级的时 间, 和在纸上写下巡查信息的时间, 提高了课堂巡查的效 率。

巡查数据的处理: 巡查完毕后, 要将所有的巡查数据 进行汇总。该校巡查数据汇总的方式是人工汇总, 具体步 骤是: 信息汇总人员先向每位课堂巡查管理人员收集巡查 记录的纸张, 然后将巡查信息录入电脑, 并生成Excel表 格。本文设计的信息汇总方式, 是借助巡查平台自动汇总, 并形成Excel表格。

巡查结果的反馈: 教学管理人员从汇总的信息中分析 出当前课堂教学过程巡查中发现的问题, 及时反映给相关 教学管理部门和授课教师。校领导通过巡查的反馈, 能了 解学校教学工作现状, 从巡查工作中反馈的问题来优化教
学质量, 提高学校办学水平。及时反馈是提高学校教学质 量的保障, 也是学校可持续发展的基础。

本文设计的巡查系统使课堂巡查过程信息化, 能够全 面完整地记录巡查信息, 保障了中等职业学校课堂巡查的 科学性和有效性[12]。

\section{4. 课堂巡查系统的实现}

在移动互联网环境下, 课堂巡查系统将服务器端部署 在腾讯云上, 腾讯云集云计算、云数据和云运营于一体, 为移动应用开发提供后端的云服务。在腾讯云的官方网站 上选择云服务器, 进入服务器配置界面, 机型选择基础配 置（1核2GB）, 镜像选择Windows Server 2012 R2, 如图 1 是腾讯云服务器配置界面。

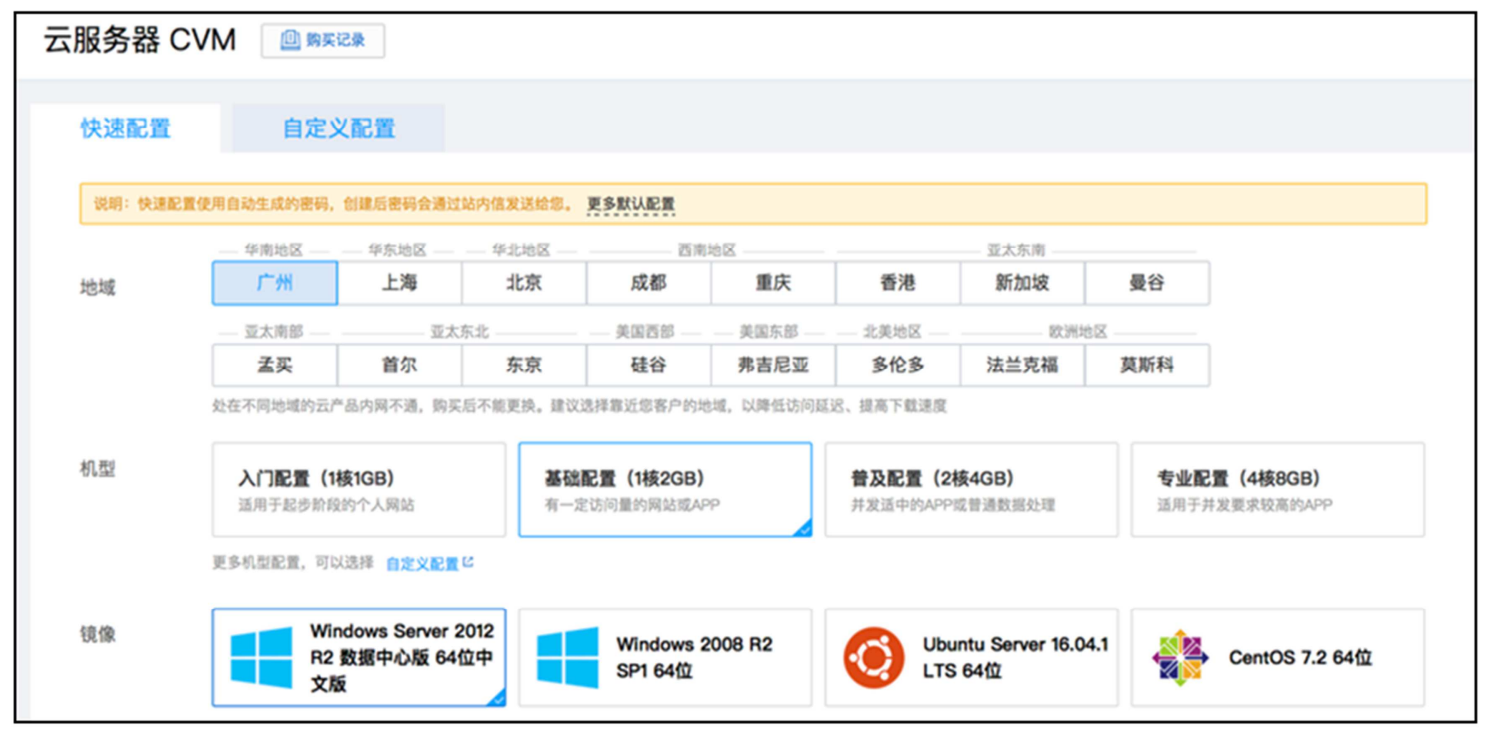

图1 腾讯云服务器配置界面。

所有信息配置完成后, 在腾讯云服务器控制台可看到 已配置完成的服务器, 在其管理界面, 将服务器开机, 通 过远程桌面连接登录到云服务器, 在本地 Windows 机器 上, 打开远程桌面连接对话框, 输入 Windows 服务器的 公网 IP, 单击“连接”, 进入后台服务器的管理操作。

课堂巡查系统有四个主要功能界面: 巡查平台的主界 面、巡查平台的教室界面、巡查信息记录界面、数据统计 界面。

巡查平台的主界面: 该页面展示了学校所有的楼层信 息, 每个楼层下面会显示相应的楼层巡查情况。如果显示: “无需巡查”, 说明该楼层没有能巡查的教室; 如果显示: “未开始巡查”, 说明该楼层的教室都还未被巡查过; 如果 显示是: “正在巡查”, 说明该楼层某些教室已被管理人员 巡查过，但还未全部被巡查完；如果显示是：“已巡查完 毕”, 说明该楼层的所有课室已经被巡查过, 该楼层的课 室无需再进行巡查。

巡查平台的教室界面: 通过巡查主界面选择需要巡查 的楼层, 进入该楼层的教室界面。该页面显示了该楼层的
所有教室, 同时每个教室下方会显示相应的教室巡查情况 信息。如果显示: “未巡查”, 说明该教室在当前时间段还 未被巡查, 没有巡查情况记录; 如果显示: “情况正常”, 说明该教室在当前时间已经被巡查, 并且巡查情况记录为 正常; 如果显示: “详细内容”, 说明该教室在当前时间已 经被巡查, 并且巡查情况记录为异常, 并在下方会显示所 有异常的信息。这样设计能使管理人员无需再进入页面, 即可直接看到记录的巡查情况信息。同时在该时间段, 已 被记录过巡查信息的教室, “修改”按钮被禁用, 这个功能 避免管理人员在同一节课，多次巡查同一间教室。巡查信 息记录界面: 从教室界面选择需要巡查的教室, 进入该教 室的巡查信息记录界面。该界面分为四个模块, 具体如下。 第一部分是课堂情况是否正常, 如果正常, 则无需再选择 第二、三部分, 如果异常则要记录具体异常的事件。第二 部分是学生课堂情况异常的数量, 这里的数量事件也就是 学生课堂情况异常的人数记录, 输入的事件项有: 睡觉人 数、玩手机人数、讲话人数、打斗人数和没课却有学生待 在教室的人数。第三部分是课堂环境情况异常的记录, 选 
择的事件是课堂环境情况异常的记录, 事件项有: 没人、 老师不在、窗户没关、投影仪没关、风扇没关、门没关、 灯没关; 第四部分是信息备注, 当上面选择事件和输入数 量事件都不能表达要记录的异常情况时, 通过信息备注这 部分手动录入异常的信息。记录完巡查信息后, 点击保存 按钮, 则会返回到上一级教室界面, 并把已经记录好的信 息, 显示在上一级教室界面相对应的课室下方。

数据统计界面: 数据统计功能是方便管理人员查看课 堂巡查管理人员的巡查数据, 点击底部菜单的统计按钮, 即可进入到数据统计界面。数据统计界面显示当日巡查情 况, 按照“课室编号-第几节”显示, 并显示巡查情况是正常 还是异常。如果是异常, 则点击情况异常按钮, 会弹出课 堂情况异常的具体情况信息内容。如图2是巡查平台示意 图。

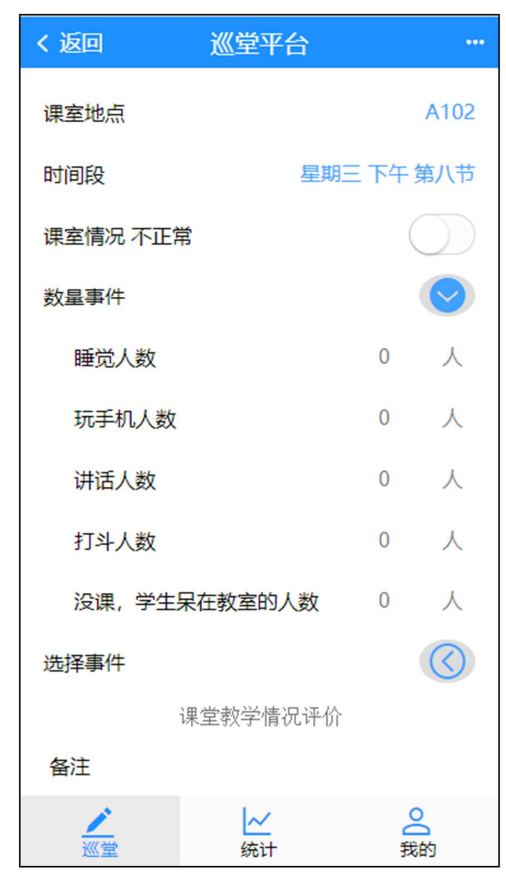

图2 巡查平台示意图。

\section{5. 结论}

本文设计的巡查系统, 适用于大部分中等职业学校, 是利用现代化的辅助教学管理系统手段 [13], 结合移动端 技术, 搭建了实时交互式的课堂巡查系统平台, 该系统在 广州某中职学校实现了试运行。课堂巡查系统代替传统的 纸质记录巡查信息的模式, 减少巡查人员的工作量, 提高 了巡查的工作效率，同时改进了传统的巡查管理方式。课 堂巡查系统记录课堂教学过程情况, 直接反馈到服务端进
行汇总, 巡查管理人员通过汇总的巡查信息获知当前课堂 教学过程中存在的问题, 并及时提供相应的解决方案, 从 而提高课堂教学过程监控的科学性和有效性。

\section{致谢}

本文为广东省联合培养研究生示范基地(991512712、 991510307)的阶段性成果之一。

\section{参考文献}

[1] 2017年中国教育事业发展大数据统计分析[Z].中商情报 网,2018。

[2] 林海翔,赵杰.中职院校教学质量监控与保障体系研究 [J]. 电 脑知识与技术,2017,13(33):159+194。

[3] 王睿哲.我国职业教育政策研究[D].沈阳师范大学,2017。

[4] 苏寒秋.多途径、多方法提高课堂教学质量监控与评价效果 [J].中国培训,2017(09):28-29。

[5] 魏蔚.面向课堂教学过程性评价的智能巡课系统研究[D].华 东师范大学,2016。

[6] 曹小其.构建中职学校教学质量监控与评价体系的思考 [J]. 机械职业教育,2015(09):1-3+8。

[7] 康硕.“互联网+”背景下学校课堂教学管理模式优化策略[J]. 科学咨询(教育科研),2018(08):25。

[8] 任逸姿.中职学校活力课堂的构建策略研究一基于课堂教 学管理的视角 [J].职业教育研究,2018(05):41-45。

[9] 吴荣涛.中等职业学校教学质量评价体系的实施办法 [J].科 技视界,2017(01):280。

[10] 李庭斌.浅议中职学校课堂教学管理过程评价探索与实践 [J].职业,2014(23):126-128。

[11] 张凯,杨再明,宋慧宁.可视化巡课系统的设计与实现 [J].中国 教育信息化,2017(13):66-69。

[12] 㚞泊伸,展程,张硕,于歆悦.基于微信平台的网络版巡课系统 开发与研究 [J].无线互联科技,2018,15(15):39-40。

[13] 吴霞.中职学校教学质量内部监测与评价体系研究[D].重庆 师范大学, 2017。 